\title{
Detection of risk clusters for deaths due to tuberculosis specifically in areas of southern Brazil where the disease was supposedly a non-problem
}

Luana Seles Alves ${ }^{1,9^{*}}$, Danielle Talita dos Santos², Marcos Augusto Moraes Arcoverde ${ }^{1}$, Thais Zamboni Berra ${ }^{1}$, Luiz Henrique Arroyo², Antônio Carlos Vieira Ramos' ${ }^{1}$, Ivaneliza Simionato de Assis', Ana Angélica Rêgo de Queiroz ${ }^{3}$, Jonas Boldini Alonso4, Josilene Dália Alves², Marcela Paschoal Popolin ${ }^{5}$, Mellina Yamamura ${ }^{2}$, Juliane de Almeida Crispim², Elma Mathias Dessunti ${ }^{6}$, Pedro Fredemir Palha ${ }^{4}$, Francisco Chiaraval-Neto ${ }^{7}$, Carla Nunes ${ }^{8}$ and Ricardo Alexandre Arcêncio ${ }^{4}$

\begin{abstract}
Background: Tuberculosis (TB) is the infectious disease that kills the most people worldwide. The use of geoepidemiological techniques to demonstrate the dynamics of the disease in vulnerable communities is essential for its control. Thus, this study aimed to identify risk clusters for TB deaths and their variation over time.

Methods: This ecological study considered cases of TB deaths in residents of Londrina, Brazil between 2008 and 2015. We used standard, isotonic scan statistics for the detection of spatial risk clusters. The Poisson discrete model was adopted with the high and low rates option used for 10,30 and 50\% of the population at risk, with circular format windows and 999 replications considered the maximum cluster size. Getis-Ord Gi* (Gi*) statistics were used to diagnose hotspot areas for TB mortality. Kernel density was used to identify whether the clusters changed over time.

Results: For the standard version, spatial risk clusters for 10,30 and $50 \%$ of the exposed population were $4.9(95 \% \mathrm{Cl}$ 2.6-9.4), 3.2 (95\% Cl: 2.1-5.7) and 3.2 (95\% Cl: 2.1-5.7), respectively. For the isotonic spatial statistics, the risk clusters for 10,30 and $50 \%$ of the exposed population were 2.8 (95\% Cl: 1.5-5.1), 2.7 (95\% Cl: 1.6-4.4), 2.2 (95\% Cl: 1.4-3.9), respectively. All risk clusters were located in the eastern and northern regions of the municipality. Additionally, through $\mathrm{Gi}^{*}$, hotspot areas were identified in the eastern and western regions.

Conclusions: There were important risk areas for tuberculosis mortality in the eastern and northern regions of the municipality. Risk clusters for tuberculosis deaths were observed in areas where TB mortality was supposedly a nonproblem. The isotonic and $\mathrm{Gi}^{*}$ statistics were more sensitive for the detection of clusters in areas with a low number of cases; however, their applicability in public health is still restricted.
\end{abstract}

Keywords: Tuberculosis, Death, Spatial analysis, Isotonic regression, Scan statistics, Cluster detection

\footnotetext{
* Correspondence: lu.selesrp@gmail.com

${ }^{1}$ Nursing Graduate Program in Public Health Nursing, University of São Paulo at Ribeirão Preto Nursing College, 3900 Avenida dos Bandeirantes, São Paulo, Brazil

${ }^{9}$ Maternal-Infant and Public Health Nursing Department, University of São

Paulo at Ribeirão Preto College of Nursing, Av dos Bandeirantes 3900,

Ribeirão Preto, São Paulo 14040-902, Brazil

Full list of author information is available at the end of the article
}

(c) The Author(s). 2019 Open Access This article is distributed under the terms of the Creative Commons Attribution 4.0 International License (http://creativecommons.org/licenses/by/4.0/), which permits unrestricted use, distribution, and reproduction in any medium, provided you give appropriate credit to the original author(s) and the source, provide a link to the Creative Commons license, and indicate if changes were made. The Creative Commons Public Domain Dedication waiver (http://creativecommons.org/publicdomain/zero/1.0/) applies to the data made available in this article, unless otherwise stated. 


\section{Background}

Tuberculosis (TB) is an ancient disease that remains a serious public health problem worldwide, affecting 30 countries that account for $87 \%$ of TB cases. The disease is among the infectious disease that kills the most people worldwide, more than HIV and malaria [1]. The World Health Organization (WHO) launched the 'End TB' strategy in 2014, aiming to achieve the elimination of TB by 2050 (< 1 case per 100,000 people), and to also reduce TB mortality by $95 \%$ by 2035 ; both goals are a large challenge in developing countries, such as Brazil [2].

In 2017, Brazil had an incidence rate of 44 cases per 100,000 inhabitants and a mortality rate of 2.4 per 100 , 000 inhabitants, with a treatment success rate of $72 \%$ among the patients monitored in 2016; this result falls short of the WHO recommendations [1]. Recently, the 'Brazil free of tuberculosis' strategy was adopted, which aims to improve access to diagnosis and quality treatment in order to achieve the goals defined by the WHO [2]. The strategy is also based on three pillars: integrated and patient-centred prevention and care; bold policies and supportive systems; and the intensification of research and innovation [3].

Currently, government predictions outline that Brazil will achieve the goal of reducing mortality by 2035 at the national level [2]; however, it is unlikely that this will happen at the subnational levels, i.e. states or municipalities. This is due to Brazil being one of the largest countries in the Americas, occupying almost 20.8\% of the hemisphere and $47.3 \%$ of South America, making it difficult to reduce the mortality rate homogeneously throughout all regions [2].

Studying the subunits of the country and thus an approximation of local health systems is relevant in order to highlight the trends and impact of tuberculosis mortality in these scenarios [4]. Mortality due to TB is defined as a socially determined event, marked mainly by social inequalities related to income, schooling, housing conditions, labour conditions, the weakness of health services (delay in diagnosis, poor diagnosis and treatment) and the absence of social politics and social protection. The risk of deaths is influenced by these factors, which range between areas in a same city, county or country $[5,6]$, therefore measuring the spatial risk to which given communities are exposed can contribute to the guidance of public policies and strategic actions [7].

This situation is not static. On the contrary, it is very dynamic and varies between the regions according to the availability of resources in terms of health, social investment, urbanisation, immigration, and modes of social organisation; therefore, the risk of disease and its impact (fatality) are influenced by these social dynamics [5]. The literature indicates that, in certain territories, deaths from $\mathrm{TB}$ are more prevalent in areas with social problems and a lack of assistance, however, there are few studies that show this, which is important for addressing the problem [6]. Therefore, measuring the spatial risk to which given communities are exposed can contribute to the guidance of public policies and the adoption of directed and focused health measures.

Tuberculosis is a low frequency event compared to diseases such as hypertension, diabetes and malaria, among others; it affects very specific and/or minor populations or groups. Therefore, because traditional techniques, such as scan statistics, require a greater number of event occurrences, their use may lead to erroneous inferences of the non-existence of the death risk of TB in a vulnerable community when it is in fact present and imminent.

The literature has a wide variety of definitions and methodological approaches for identifying clusters [8]; various methods are compared, contrasted and matched, aiming to overcome the issue of unknown and underdiagnosed clusters and to ensure the validity, sensitivity and accuracy of the studies [9].

Through a literature review of TB mortality risk clusters, only three articles were identified in Brazil $[6,8,9]$, however all of these articles applied standard scan statistics. Isotonic spatial scan statistics and Getis-Ord Gi* statistics $\left(\mathrm{Gi}^{*}\right)$ can be used complementarily to increase the chances of identifying a cluster, mainly in areas where the event is more rare. Although these statistics are interesting resources to identify spatial risk clusters in the case of rare phenomena, their application in the area of geoepidemiology is still very limited. Thus, this study aimed to identify risk clusters for TB deaths, specifically in areas where TB supposedly does not seem to be a problem.

\section{Methods \\ Study design and setting}

This ecological study [10] was carried out in the municipality of Londrina, which is a centre for business, technology, research and health development [11]. It is situated at the following geographical coordinates: $23^{\circ} 18^{\prime} \mathrm{S}$ latitude and $51^{\circ} 09^{\prime} \mathrm{W}$ longitude [12]. Figure 1 illustrates the location of the municipality.

The municipal population is 548,249 inhabitants, of whom 493,520 are concentrated in the urban area, which is the second most populous city of Paraná. The municipal population density is 330.95 inhabitants $/ \mathrm{km}^{2}$ [12].

In terms of social indicators, the municipality has a Municipal Human Development Index (MHDI) of 0.78, classified as a high HDI (0.700 to 0.799$)$ according to the United Nations Development Program (UNDP) [13]. Longevity is the attribute that contributes most to the MHDI, with an index of 0.837 , followed by income, with an index of 0.789 , and education, with an index of 0.712 . 

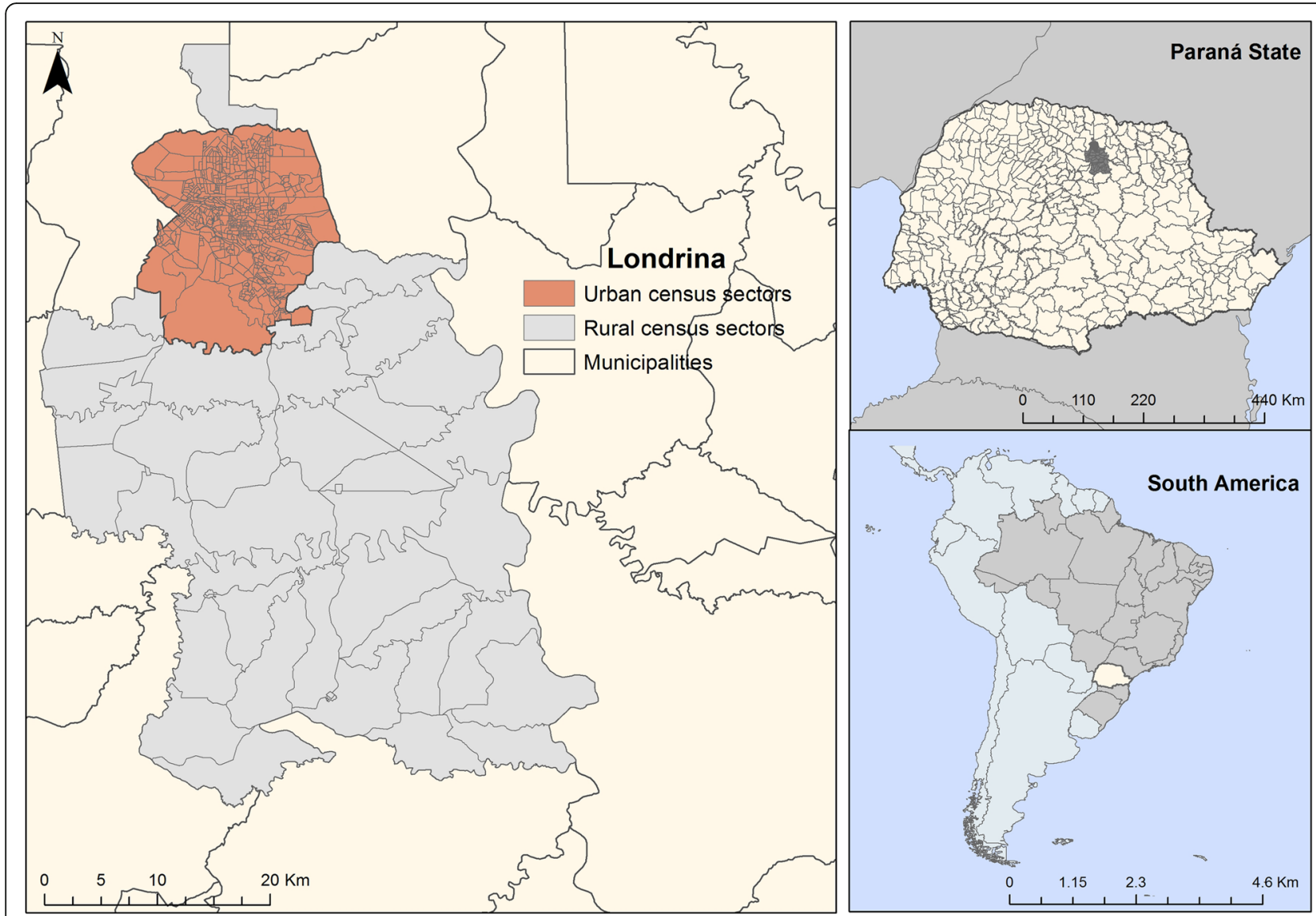

Fig. 1 Map of the studied municipality and its geographical location. Londrina, Brazil (2008-2015)

Regarding social inequality, the municipality presents a Gini coefficient of 0.42 , suggesting that there is an inequality of income distribution, and a poverty rate of $36.49 \%$ [13].

The municipality has 56 primary health units (PHUs), with 86 family health strategy (FHS) teams distributed in 54 PHUs. FHS coverage is $58.62 \%$, with 32 hospitals and two emergency care units (ECUs) $[11,12]$.

In 2015, Londrina had a TB incidence rate of 32.95/ 100,000 inhabitants, a bacillary TB incidence rate of $17.16 / 100,000$ inhabitants and a mortality rate of $0.7 /$ 100,000 inhabitants [14].

\section{Study observation units}

The analysis units of the study were census tracts [15]. The municipality of Londrina has 713 census tracts; the 678 tracts that are considered to be urban were used in this study.

\section{Study population and period}

The study population consisted of cases of deaths caused by $\mathrm{TB}$, with the Declaration of Death (DD) showing codes A15.0 to A19.9, according to the International
Classification of Diseases (ICD version 10). This corresponded to all clinical forms of $\mathrm{TB}$, and was assessed over the period from 2008 to 2015.

\section{Source of information and data collection}

Data were obtained from two different sources. The first source was 2010 Demographic Census of the Brazilian Institute of Geography and Statistics to obtain the maps data, and the second source was the mortality information system (MIS) of the Health Surveillance Department of the Municipal Health Department of Londrina, BR. The use of the MIS is justified because it was one of the pioneering systems to be founded in Brazil [16].

\section{Data analysis}

In the first step, descriptive statistics were performed, including the calculation of absolute frequency and proportion measures for the categorical variables and location (mean and median) and dispersion (standard deviation) measures for the continuous variables, using Statistica (v12.0) software. 
Subsequently, the geographic coordinates of each address were searched using the free access Google Earth technology and the geo-referencing technique of the cases was performed using the Terraview (v4.2.2) software. The SaTScan v9.4.2 software was used to identify the risk areas for TB mortality, initially applied to the standard, and then the isotonic version $[17,18]$.

Scan statistics is a technique developed by Kulldorff and Nagarwalla [13]. It consists of circles that move throughout the study area around the centroids, which correspond to the centre of each territorial unit under analysis [19]. The formation of the spatial clusters is based on the calculation of the number of events found within each circle. If the observed value of the region delimited by the circle is larger than expected, it is called a risk cluster; if the value is lower than expected, it is called a low-risk or protective cluster. This procedure is repeated until all centroids are tested [20].

In the centralisation process, the log likelihood ratio (LLR) of each potential cluster is formulated based on the calculation of the mortality that is observed and expectedin and out of the circular window in which the $p$-value is assigned, according to the following formula [21]:

$$
\text { LLR }=\log \left(\frac{\mathrm{O}_{\text {in }}}{\mathrm{E}_{\text {in }}}\right)^{\mathrm{Oin}}\left(\frac{\mathrm{O}-\mathrm{O}_{\text {in }}}{\mathrm{O}-\mathrm{E}_{\text {in }}}\right)^{\mathrm{O}-\mathrm{O}_{\text {in }}}
$$

in which $\mathrm{O}$ represents the observed cases and $\mathrm{E}$ represents the expected cases. In this way, $\mathrm{O}_{\text {in }}$ and $\mathrm{E}_{\text {in }}$ denote the number of observed and expected cases in the window, respectively. $E_{\text {in }}$ is calculated by multiplying the deaths due to TB by the population of the census tracts. The higher the LLR, the less likely the cluster detection occurred due to chance [22].

After the formation of the cluster, the software also presents the spatial relative risk (SRR) value [23], which is obtained through an equation [24] that corresponds to the estimated risk within a cluster divided by the estimated risk outside the cluster. The SRR is calculated by taking into account the observed cases divided by the expected cases within the cluster, all divided by the observed cases divided by the expected cases outside the cluster. The equation is:

$$
S R R=\frac{N_{z} / E_{z}}{\left(N-N_{z}\right) /\left(E_{A-} E_{Z}\right)}
$$

where $\mathrm{N}$ is the total number of cases, $\mathrm{NZ}$ is the number of cases in the $\mathrm{Z}$ cluster, $\mathrm{EA}$ is the expected number of cases in the region under the null hypothesis, and EZ is the expected number of cases in the $Z$ area under the null hypothesis.

The difference between the standard and isotonic methods lies in the number of circular windows generated during the centralisation procedure; the isotonic version, instead of developing only one circular window, uses a set of different sized, overlapping circles, centred on the same centroid. It also starts from the alternative hypothesis that the mortality rate is highest within the innermost circle, a little lower between the first and second circles, and so on, until the final circle $[18,24]$.

In the isotonic version of a given centroid, the risk is modelled as higher within some unknown distance $(d)$ of the centroid compared to a greater distance from the same centroid. This means that the risk is modelled as a function $r(d)$ of the distance from the centroid, and that it uses the steps in a risk function with a single discontinuity in $d[25,26]$.

The risk function can be classified as a non-increasing function, i.e. the greater the distance from the centroid of the territorial unit of analysis, the smaller the spatial risk for the occurrence of death due to TB. After the identification of the purely spatial risk clusters, to assess the reliability of the SRR values, the respective 95\% confidence intervals (95\% CI) were calculated [27].

In terms of the spatial clusters, the Poisson method was adopted, with the high and low rates option used for the two analyses, and 10, 30 and $50 \%$ of the population at risk, with circular format windows and 999 replications considered as the maximum cluster size [28, 29].

In the third step, the $\mathrm{Gi}^{*}$ statistical technique was used to analyse the spatial association of TB mortality. For this, it was necessary to calculate the $\mathrm{TB}$ mortality rate standardised by sex and age (TxMTBi), with age classified as less than or equal to the median, or greater than the median ( 56 years), according to the formula:

$$
\text { TxMTBi }=\frac{\sum \text { of the standardised by age } \mathrm{X} 100,000}{\sum \text { of the standard population }} \times \frac{1}{8}
$$

Next, to estimate the radius of the distance used in the $\mathrm{Gi}^{*}$, the Incremental Spatial Autocorrelation (ISA) tool provided by ArcGIS (10.5) was used. The ISA was tested for 30 distances, in which the result of the most pronounced distance was $3143.28 \mathrm{~m}$ with $p<0.01$ [30, 31]. Also, for the spatial association analysis, the weight matrix normalised by distance was created using Geoda version 1.8 software.

The Getis-Ord General G, G(d), analysis was performed in ArcGIS (v.10.5) software. The G(d) consists of a global index to evaluate the spatial association of an attribute based on statistical distances and calculated from a sum of values for a given distance, according to the following formula [32]:

$$
G(d)=\frac{\sum_{i=1}^{n} \sum_{j=1}^{n} w_{i j}(d) x_{i} x_{j}}{\sum_{i=1}^{n} \sum_{j=1}^{n} x_{i} x_{j}}, j \text { not equal to } i
$$

where $n$ corresponds to the number of areas, $\mathrm{W}_{\mathrm{ij}}$ is the value in the proximity matrix for region $i$ with region $j$ 
as a function of distance (d), and $x_{i}$ and $x_{j}$ are the values of the attributes considered in the areas $i$ and $j$.

The value of $G(d)$ is provided by a $Z$ score, ranging from +3 to -3 , which determines whether the attributes with high or low values are spatially grouped, with higher $\mathrm{Z}$ scores indicating more extreme grouping in the region, called hotspots, lower Z-scores indicating low value groupings, called coldspots, and values of 0 indicating no grouping [33, 34]. In this sense, with the intention of examining the spatial patterns in detail, the $\mathrm{Gi}^{*}$ local association indicator was used. In the $\mathrm{Gi}^{*}$, the values for each location, that is, each census sector, are considered from a neighbourhood matrix.

The pseudo-significance test was used to certify the statistical validity of the results [35]. A type I error of $5 \%$ was fixed as statistically significant $(p<0.05)$ for all the tests.

\section{Kernel density}

An estimation of the density of the nucleus was performed every year to identify whether the conglomerates were changing over time. This analysis consisted of an exploratory interpolation in which the density was generated for the visual identification of hotspot areas, which belong to regions with a higher density of $\mathrm{TB}$ deaths [36]. A radius of $3143.28 \mathrm{~m}$ was considered, according to the analysis performed through ArcGIS (v.10.5) software. Thematic maps were also constructed using this software.

\section{Ethical approval and consent to participate}

The maps data from 2010 Demographic Census of the Brazilian Institute of Geography and Statistics are open data, and the data from the MIS were authorized of the Health Surveillance Department of the Municipal Health Department of Londrina,BR. This study was approved by the Research Ethics Committee of the School of Nursing of the University of São Paulo, Ribeirão Preto Campus, in accordance with the Guidelines and Regulatory Standards for Research with Human Subjects, Resolution No. 196/96 of the National Health Council, under Certificate of Presentation for Ethical Appreciation No. 56305516.0.0000.5393, issued on 11 December 2015. A signed consent form was not necessary as secondary data were used and the participants were not identified.

\section{Results}

A total of 61 deaths due to TB were identified, the characteristics of which are described in Table 1 . According to this table, the mean age was 56.9 years with a standard deviation (SD) of $17.8 ; 49(80.3 \%)$ were male, 39 (63.9\%) were white, 17 (27.9\%) were married and $20(32.8 \%)$ had a high school education. According to Table 1, $32(52.4 \%)$ presented the pulmonary clinical form of TB. All identified cases were georeferenced, with a general municipal mortality rate of 1.5 cases per 100 , 000 inhabitants.

Regarding the application of the standard for high rates, a risk cluster was identified for each percentage of the population exposed, i.e. 10,30 and $50 \%$, with the SRR and 95\% CI values expressed in Fig. 2.

In Fig. 2, the clusters of risk covered the north and east regions of the municipality, with 12 deaths in the cluster with $10 \%$ of the population at risk and 29 deaths for 30 and $50 \%$. Also, usingk the traditional scan, for low rates and $10 \%$ of the population exposed, a protection cluster was identified in the northwestern region of the municipality, where there were no deaths due to $T B$, whereas for 30 and $50 \%$ of the population at risk, the protection cluster involved the entire southern region of the municipality, with 5 deaths for each cluster.

Referring to the isotonic version, as seen in Fig. 3, spatial risk clusters were also found in the northern and eastern regions of the municipality, demonstrating that there was no change in the location of the risk clusters. The protection clusters also maintained the same location as in the traditional scan. The SRR and 95\% CI values are described in Fig. 3.

In the isotonic version, the steps in the risk function are present, which corresponds to the multiple circular windows formed during the centralisation process of the scan. This also maximises the LLR. These steps allowed for the verification of the intensity of mortality within the clusters. Thus, for the risk cluster with $10 \%$ of the population, step 1 had the lowest radius $(0.3 \mathrm{~km}$; Table 2$)$ and the highest SRR value (20.8; 95\% CI 7.5-57.1), totalling 4 deaths, whereas step 2 had a radius of $1.8 \mathrm{~km}$ and a SRR of 2.05 (95\% CI 1.1-3.0), totalling 14 deaths.

The risk cluster for $50 \%$ of the population at risk had six steps, with step 1 having a radius of $0.3 \mathrm{~km}$ and SRR of 24.4 (95\% CI 8.9-67.3), with 4 deaths, and step 6 having a radius of $3.9 \mathrm{~km}$ and SRR of 1.4 (95\% CI 1.3-3.9), with 38 deaths. In this way, the smaller the cluster radius of the risk clusters, the higher the SRR value.

Regarding the protection clusters, step 1 had the lowest SRR, as it occurred in the cluster for $30 \%$ of the population at risk, in which step 1 presented a radius of $4.0 \mathrm{~km}$ and SRR of 0 and step 2 had a radius of $6.0 \mathrm{~km}$ and SRR of 0.25 (95\% CI 0.1-0.6), totalling 5 deaths, i.e. the smaller the radius, the smaller the SRR value.

Table 2 shows the spatial characteristics of TB deaths within the clusters identified through the isotonic version according to the steps in risk function.

Table 3 compares 346 the data obtained through the standard scan and the isotonic scan.

Table 3 shows that the isotonic version covered more census tracts due to the larger radius dimensions. For 10 and $50 \%$ of the population, there were 60 and 281 
Table 1 Characteristics of the individuals who died of tuberculosis in Londrina, Brazil (2008-2015)

\begin{tabular}{|c|c|c|}
\hline Variable & $n$ & $\%$ \\
\hline \multicolumn{3}{|l|}{ Age (years) } \\
\hline$<19$ & 1 & 1.6 \\
\hline 20-39 & 8 & 13.1 \\
\hline $40-59$ & 27 & 44.3 \\
\hline$\geq 60$ & 25 & 41.0 \\
\hline Median & 56 & \\
\hline Mean & 56.9 & \\
\hline \multicolumn{3}{|l|}{ Gender } \\
\hline Male & 49 & 80.3 \\
\hline Female & 12 & 19.7 \\
\hline \multicolumn{3}{|l|}{ Skin colour/ethnicity } \\
\hline White (Caucasian) & 39 & 63.9 \\
\hline Black (African) & 9 & 14.8 \\
\hline Yellow (Asian) & 4 & 6.6 \\
\hline Brown (Mixed race) & 9 & 14.8 \\
\hline \multicolumn{3}{|l|}{ Marital status } \\
\hline Single & 17 & 27.9 \\
\hline Married & 23 & 37.7 \\
\hline Widowed & 6 & 9.8 \\
\hline Divorced & 6 & 9.8 \\
\hline Steady partner & 2 & 3.3 \\
\hline No response & 7 & 11.5 \\
\hline \multicolumn{3}{|l|}{ Level of education } \\
\hline No schooling & 1 & 1.6 \\
\hline Elementary education & 12 & 19.7 \\
\hline High school education & 20 & 32.8 \\
\hline Higher education & 15 & 24.6 \\
\hline No response & 13 & 21.3 \\
\hline \multicolumn{3}{|l|}{ Occupation } \\
\hline Retired/pensioner & 13 & 21.3 \\
\hline Homemaker & 7 & 11.5 \\
\hline Miscellaneous & 28 & 45.9 \\
\hline No response & 13 & 21.3 \\
\hline \multicolumn{3}{|l|}{ Place of death } \\
\hline Hospital & 54 & 88.5 \\
\hline Home & 7 & 11.5 \\
\hline \multicolumn{3}{|l|}{ Received medical assistance } \\
\hline Yes & 32 & 52.5 \\
\hline No & 2 & 3.3 \\
\hline No response & 27 & 44.3 \\
\hline
\end{tabular}

Table 1 Characteristics of the individuals who died of tuberculosis in Londrina, Brazil (2008-2015) (Continued)

\begin{tabular}{lll}
\hline Variable & $\mathrm{n}$ & $\%$ \\
\hline Diagnosis confirmed by further examination & & 23.0 \\
Yes & 14 & 3.3 \\
No & 2 & 73.8 \\
No response & 45 & \\
Diagnosis confirmed by surgery & & 1.6 \\
Yes & 1 & 24.6 \\
No & 15 & 73.8 \\
No response & 45 & \\
Diagnosis confirmed by necropsy & & 8.2 \\
Yes & 5 & 59.0 \\
No & 36 & 32.8 \\
No response & 20 & 27.9 \\
Death certified by & & 31.1 \\
Assistant & 17 & 3.3 \\
Substitute & 19 & 52.4 \\
Death Surveillance Service & 2 & 47.5 \\
TB site & & \\
Pulmonary & 32 & \\
Extra-pulmonary & 29 & \\
\hline
\end{tabular}

Source: MIS Londrina, BR 2016

sectors in the isotonic versus 32 and 153 sectors in the traditional version, respectively.

In terms of TB cases, the traditional version captured fewer cases than the isotonic version, with the traditional version presenting 29 deaths for $50 \%$ of the population, compared to 38 deaths in the isotonic version. The SRR in the traditional version remained larger than that in the isotonic version, ranging from 3.2 to 4.9 and 2.2 to 2.8 , respectively; however, in the isotonic version, the SRR assumed higher standards within the steps, ranging from 1.4 to 24.4.

A similar case occurred for the mortality rates, with the traditional version calculating 3.4 to 6.4 deaths per 100,000 inhabitants, whereas the isotonic version calculated 2.3 to 3.7 deaths per 100,000 inhabitants. However, the rates within the steps ranged from 3.0 to 27.0 deaths per 100,000 inhabitants.

For the protection clusters, the data were similar when considering 10 and $30 \%$ of the population at risk, however, when the size of the cluster was changed to $50 \%$ of the population, the isotonic version grouped more census sectors, with 261 sectors and more TB deaths, totalling 8 . An important aspect to be emphasised is the LLR values; as Table 3 shows, in the isotonic version, the LLRs were increased for both the risk and protection clusters, highlighting that the randomness of the clusters in the isotonic version was lower than in the traditional version. 


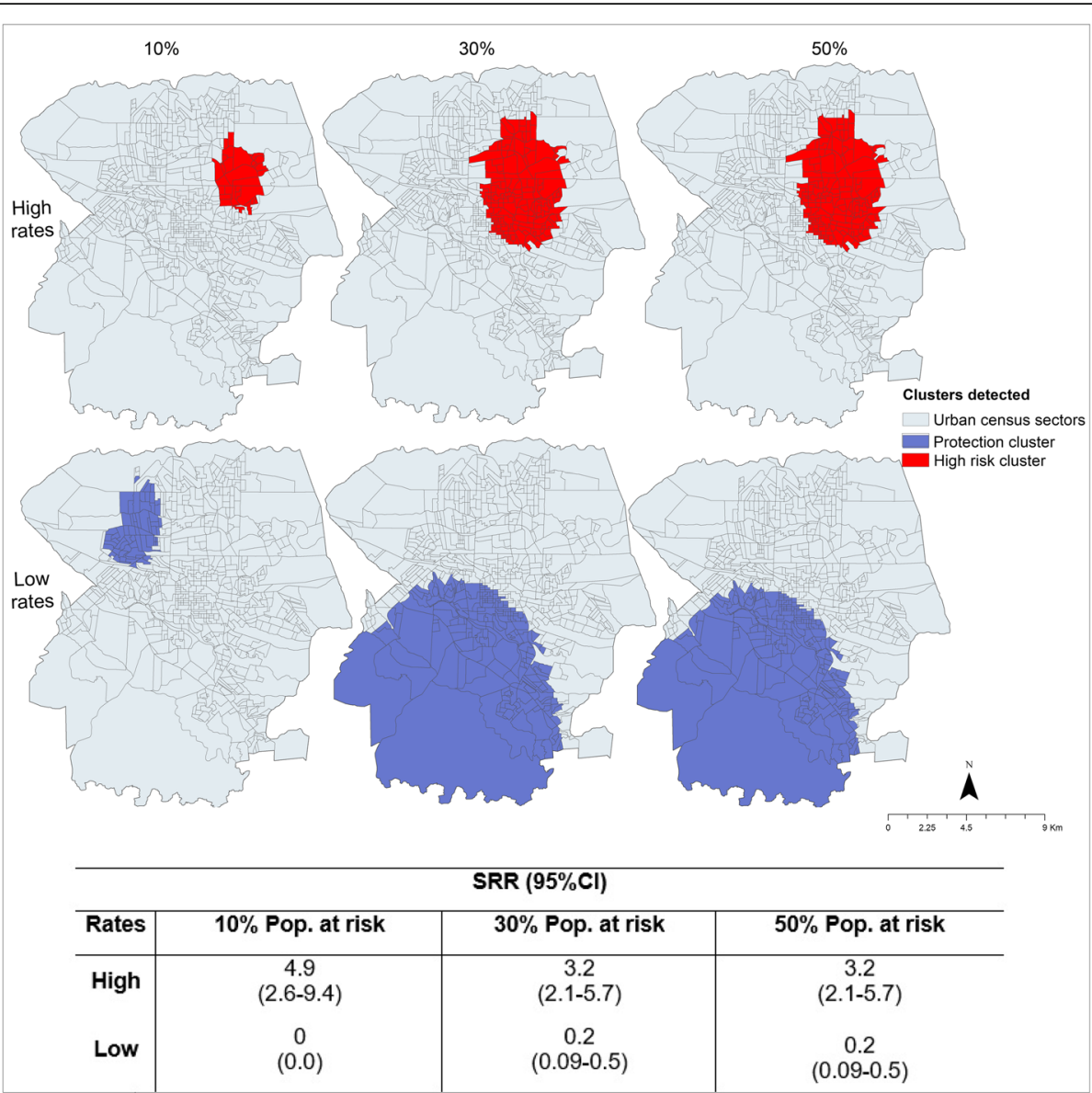

Fig. 2 Clusters of high-low risk for TB mortality according to the exposed population, Londrina, Brazil (2008-2015)

Regarding the spatial association, Fig. 4 shows the hotspots and coldspots detected by the global and local analysis of the Getis-Ord statistic. The general index of the Getis-Ord statistic (Fig. 4b) had a value of 0.002 , demonstrating a positive spatial relationship. The local analysis $\mathrm{Gi}^{*}$ (Fig. 4a) demonstrated the formation of hotspots in the eastern regions, with 95\% confidence, and in the western region, with $99 \%$ confidence, where the Gi Z-score was higher than 1.96. Coldspots were also found in the northwestern and southern regions of the municipality, with 95\% confidence level. The pseudosignificance test (Fig. 4b) confirmed both the statistical significance of the analysis, with $p<0.01$, and the nonrandomness of the clusters.

Figure 5 shows the distribution of the highest density of deaths due to TB for each year of this study.

\section{Discussion}

This study aimed to identify risk clusters for TB deaths, specifically in areas where TB supposedly does not seem to be a problem. We observed that the isotonic version covered a greater area of risk than the traditional method, areas that would be considered to be non-problematic or unknown by health care services.

The difference between the traditional method and the isotonic version consists of the number of circular windows generated during the centralisation procedure. The isotonic version, instead of developing only one circular window, uses a set of different sized, overlapping circles, centred on the same centroid. It also starts from the alternative hypothesis that the mortality rate is highest within the innermost circle, a little lower between the first and second circles, and so on, until the final circle [18]. Despite the isotonic version evaluating a window with multiple circles, only a single circle provides the highest likelihood and therefore defines the most probable cluster; in this way, the isotonic version and $\mathrm{Gi}^{*}$ proved to be more suitable spatial techniques to analyse territorial subunits and with rarer events.

When $\mathrm{Gi}^{*}$ was performed, a new hotspot region was identified, which would have been unknown or underdiagnosed by scan statistics. Although this technique does not follow the same analysis pattern 


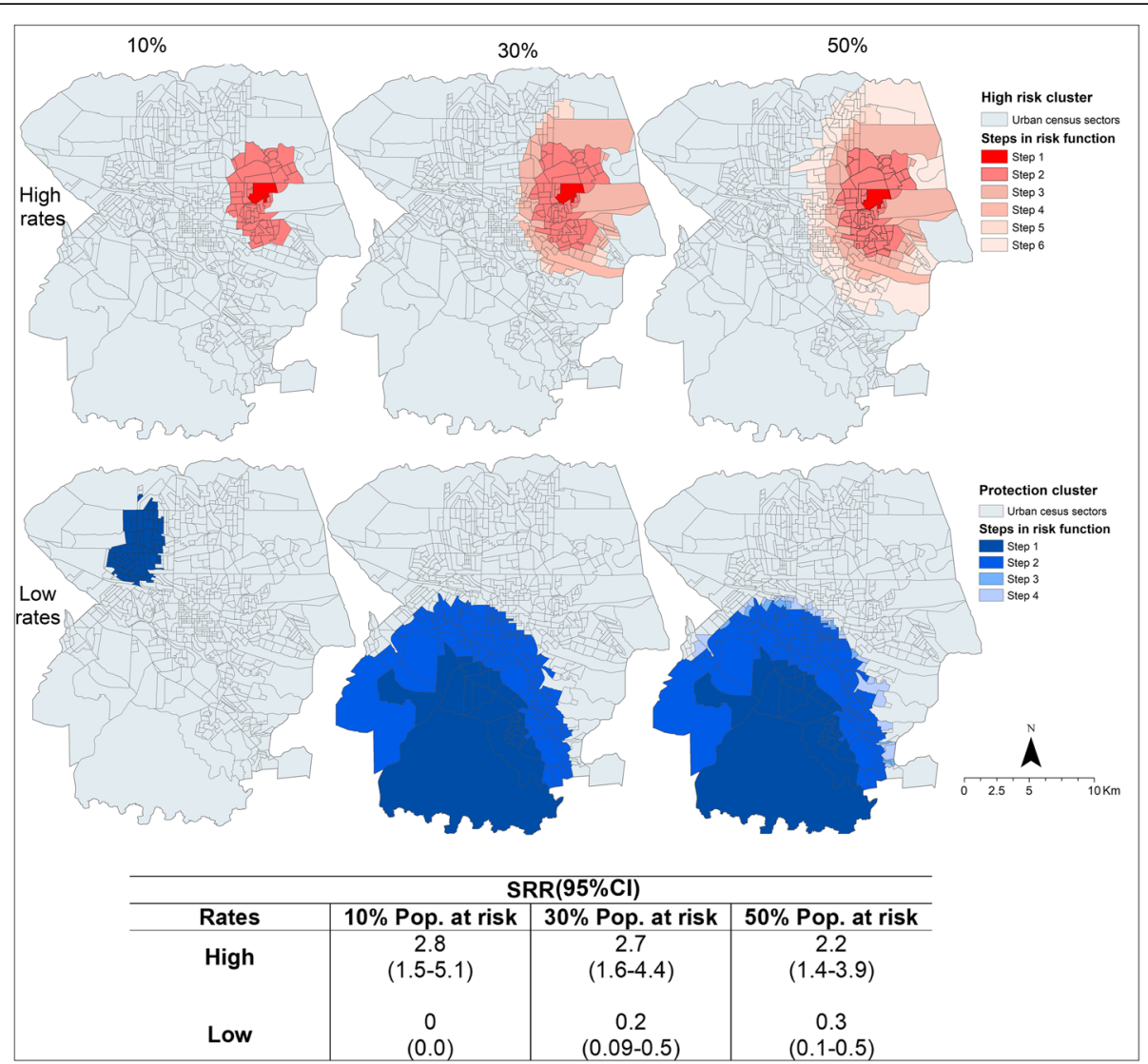

Fig. 3 Clusters of TB deaths in the exposed population, identified through isotonic spatial scan statistics, Londrina, Brazil (2008-2015)

as scan statistics (Fig. 4), it diagnosed clusters in areas where TB was supposedly not a problem.

These findings are important to keep in mind when considering the procedures and tools that have been used by health surveillance and health care workers. When the results are negative, it is likely that these areas will not be prioritised in terms of active TB case finding, the education of health professionals and community, and investigations into health care services, among other actions [37, 38]. When risk clusters for TB deaths are identified, these areas might be prioritised in terms of new resources and investment to improve health conditions and access [6, 7]. thus advancing health equity. The results might motivate integration between epidemiological surveillance activities and Primary Health Care and this way, early diagnosis, the active search for respiratory symptomatology, and the follow-up of patients.

Due to the development of information technology, epidemiology has added a series of modern instruments to its arsenal, which allow for the consideration of the issue of space and to deepen reflections on social relations and the conditions that differ between the risk of dying and living in the different areas under investigation; this study has produced important contributions to these areas.
In relation to the profile of the deaths investigated in the study, the most affected age group corresponded to the economically active population, corroborating the findings in the literature [39, 40]. Another important finding was that, in spite of the predominance of middle-aged deaths, deaths in older adults were also highlighted as, due to the increased longevity of the population, the municipality is facing an increasing number of older adults with TB. Senility has been found to be a risk factor for TB disease [41-43]. Males were more frequently affected by death, as was the case in the studies by Dale [44], Beyene [45] and Ferrer [46], which associated this fact with the cultural, economic and social factors related to TB exposure.

Studies show that TB mortality in Brazil occurs predominantly in the non-white population [9, 47, 48]. However, in the present study, the white population was most affected. This was probably due to the fact that the municipality was colonised by Europeans and $70 \%$ of the population identifies as white [26, 49]. The majority of cases had a complete high school education, unlike the findings in the literature, which report that the level of schooling is an essential tool for understanding TB patients in terms of their clinical situation and adherence 
Table 2 Risk clusters for TB deaths, according to the steps in risk function, in Londrina, Brazil (2008-2015)

\begin{tabular}{|c|c|c|c|c|c|c|c|c|c|}
\hline Rate & $\begin{array}{l}\text { Pop. at } \\
\text { risk (\%) }\end{array}$ & $\begin{array}{l}\text { Steps in } \\
\text { risk function }\end{array}$ & $\begin{array}{l}\text { No. census } \\
\text { sectors }\end{array}$ & Pop. of cluster & $\begin{array}{l}\text { Annual } \\
\text { cases/100,000 }\end{array}$ & No. Cases & $\begin{array}{l}\text { Expected } \\
\text { cases }\end{array}$ & $\operatorname{SRR}^{\mathrm{a}}(95 \% \mathrm{Cl})$ & Radius (km) \\
\hline \multirow[t]{13}{*}{ High } & \multirow[t]{2}{*}{10} & 1 & 2 & 1846 & 27.0 & 4 & 0.2 & $20.8(7.5-57.1)$ & 0.3 \\
\hline & & 2 & 62 & 47193 & 3.7 & 14 & 5.7 & $2.05(1.1-3.7)$ & 1.8 \\
\hline & \multirow[t]{5}{*}{30} & 1 & 2 & 1846 & 27.0 & 4 & 0.2 & $24.4(8.9-67.3)$ & 0.3 \\
\hline & & 2 & 71 & 55843 & 3.5 & 16 & 6.8 & $2.43(1.4-4.3)$ & 1.9 \\
\hline & & 3 & 107 & 79956 & 3.2 & 21 & 2.9 & $2.31(1.3-3.9)$ & 2.5 \\
\hline & & 4 & 130 & 95969 & 3.1 & 24 & 3.6 & $2.09(1.2-3.4)$ & 2.8 \\
\hline & & 5 & 149 & 112273 & 3.0 & 27 & 2.0 & $2.03(1.2-3.3)$ & 2.9 \\
\hline & \multirow[t]{6}{*}{50} & 1 & 2 & 1846 & 27.0 & 4 & 0.2 & $24.46(8.9-67.3)$ & 0.3 \\
\hline & & 2 & 71 & 55843 & 3.5 & 16 & 6.8 & $2.43(1.4-4.3)$ & 1.9 \\
\hline & & 3 & 107 & 79956 & 3.2 & 21 & 2.9 & $2.31(1.3-3.9)$ & 2.5 \\
\hline & & 4 & 130 & 95969 & 3.1 & 24 & 1.9 & $2.09(1.2-3.4)$ & 2.8 \\
\hline & & 5 & 149 & 112273 & 3.0 & 27 & 2.0 & $2.03(1.2-3.3)$ & 2.9 \\
\hline & & 6 & 281 & 203846 & 2.3 & 38 & 11.7 & $1.4(1.3-3.9)$ & 3.9 \\
\hline \multirow[t]{7}{*}{ Low } & 10 & 1 & 63 & 53032 & 0 & 0 & 6.1 & $0(0.0)$ & 1.6 \\
\hline & \multirow[t]{2}{*}{30} & 1 & 31 & 23448 & 0 & 0 & 2.7 & $0(0.0)$ & 4.0 \\
\hline & & 2 & 216 & 35782 & 1.7 & 5 & 15.5 & $0.25(0.1-0.6)$ & 6.0 \\
\hline & \multirow[t]{4}{*}{50} & 1 & 31 & 23448 & 0 & 0 & 2.7 & $0(0.0)$ & 4.0 \\
\hline & & 2 & 217 & 144348 & 0.4 & 5 & 15.6 & $0.23(0.09-0.6)$ & 6.0 \\
\hline & & 3 & 230 & 154346 & 0.5 & 6 & 1.3 & $0.6(0.1-0.5)$ & 6.0 \\
\hline & & 4 & 261 & 156194 & 0.6 & 8 & 2.3 & $0.63(0.1-0.6)$ & 6.3 \\
\hline
\end{tabular}

${ }^{\mathrm{a}}$ Spatial relative risk

Table 3 Comparative analysis of standard and isotonic scans of TB mortality, Londrina, Brazil (2008-2015)

\begin{tabular}{|c|c|c|c|c|c|c|c|}
\hline \multirow{2}{*}{$\begin{array}{l}\text { Rate } \\
\text { Pop. at risk (\%) }\end{array}$} & & \multicolumn{3}{|l|}{ High } & \multicolumn{3}{|l|}{ Low } \\
\hline & & 10 & 30 & 50 & 10 & 30 & 50 \\
\hline \multirow[t]{2}{*}{ No. census sectors } & Standard & 32 & 153 & 153 & 63 & 216 & 217 \\
\hline & Isotonic & 60 & 149 & 281 & 63 & 216 & 261 \\
\hline \multirow[t]{2}{*}{ Pop. of cluster } & Standard & 22993 & 102433 & 102433 & 53032 & 143762 & 144328 \\
\hline & Isotonic & 47193 & 112265 & 203830 & 53032 & 143762 & 172652 \\
\hline \multirow[t]{2}{*}{ Annual cases $/ 100,000$} & Standard & 6.4 & 3.4 & 3.4 & 0 & 0.4 & 0.4 \\
\hline & Isotonic & 3.7 & 3.0 & 2.3 & 0 & 0.4 & 0.6 \\
\hline \multirow[t]{2}{*}{ No. cases } & Standard & 12 & 29 & 29 & 0 & 5 & 5 \\
\hline & Isotonic & 14 & 27 & 38 & 0 & 5 & 8 \\
\hline \multirow[t]{2}{*}{ Expected cases } & Standard & 2.9 & 13.3 & 13.3 & 6 & 18.3 & 18.4 \\
\hline & Isotonic & 5.9 & 14 & 25.8 & 6.1 & 18.3 & 22 \\
\hline \multirow[t]{2}{*}{ Radius (km) } & Standard & 1.4 & 2.4 & 2.4 & 1.6 & 5.9 & 6.0 \\
\hline & Isotonic & 1.8 & 2.9 & 3.9 & 1.6 & 5.9 & 6.3 \\
\hline \multirow[t]{2}{*}{$\operatorname{LLR}^{\mathrm{a}}$} & Standard & 8.7 & 9.7 & 9.7 & 6.4 & 8.7 & 8.7 \\
\hline & Isotonic & 9.6 & 12.3 & 12.7 & 6.4 & 9.5 & 9.9 \\
\hline \multirow[t]{2}{*}{$p$-value } & Standard & 0.05 & $0.02^{* *}$ & $0.03^{* *}$ & 0.05 & $0.04^{* *}$ & $0.04^{* *}$ \\
\hline & Isotonic & $0.04^{* *}$ & $0.01^{* *}$ & $<0.01^{* *}$ & 0.05 & $0.02^{* *}$ & $0.02^{* *}$ \\
\hline
\end{tabular}




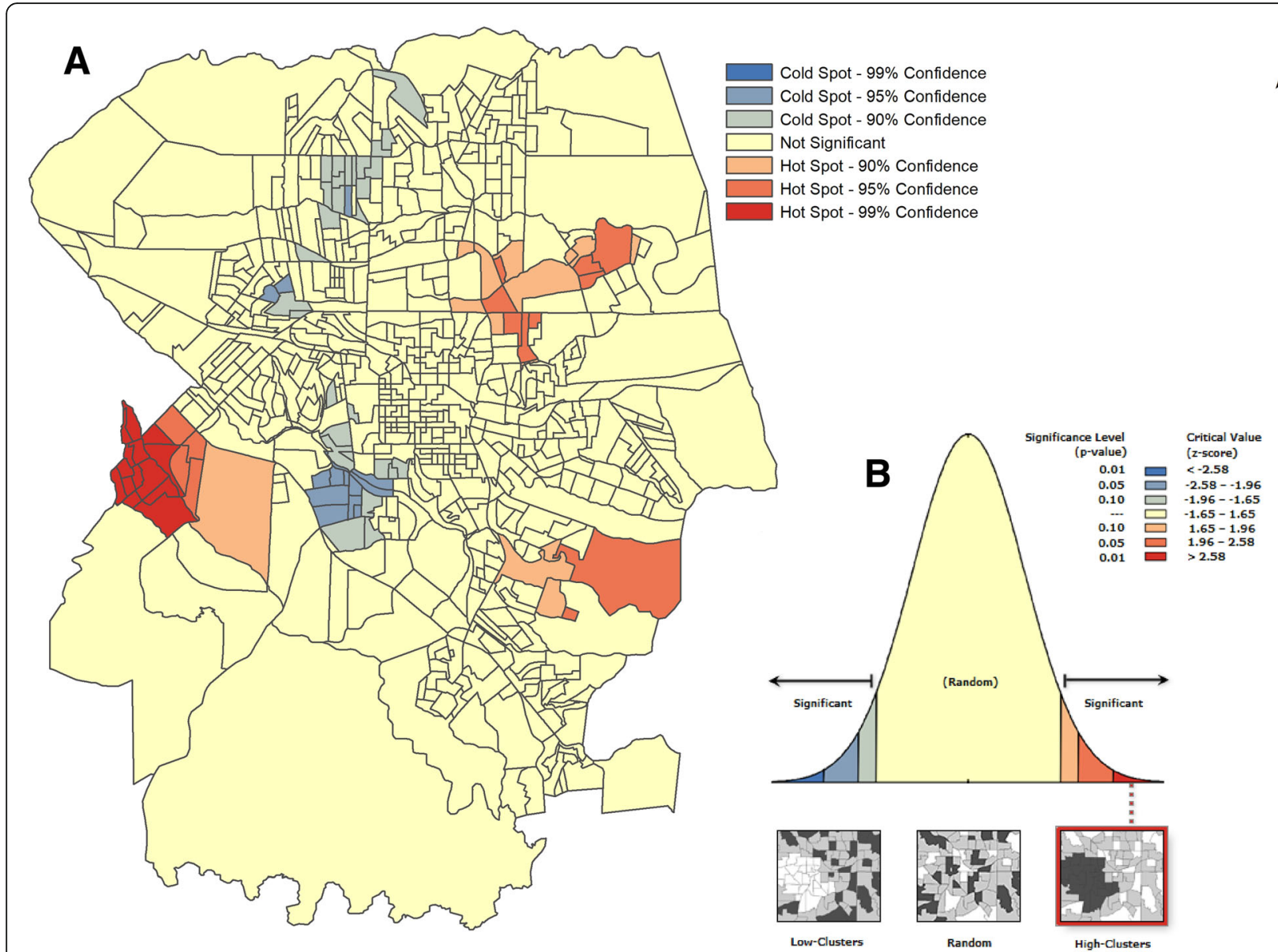

Fig. 4 Hotspots and coldspots related to the risk of TB mortality, according to Gi*, Londrina, Brazil (2008-2015). a Gi* local spatial association b Level of statistical significance of the General G statistics

to treatment, with increased education reducing the index and risk of death [50-52].

Regarding occupation, retirees/pensioners were prevalent. According to Cavalcante [53], this is due to the fact that retirees present greater vulnerability in terms of economic conditions, difficulties in transportation to health services, abandonment by family members and the difficulties in implementing public policy that meet the health demands of older adults.

The majority of the deaths occurred in the hospital after receiving medical care, with this finding highlighting difficulties in the early diagnosis of $\mathrm{TB}$ and the consequent delay in the treatment of these patients; this may be due to shortcomings in the primary healthcare system. It is important to highlight that the coverage of the FHS is approximately $58 \%$ in the municipality [53-56].

This study showed the pulmonary form of TB to be the most frequent in cases of death, which has also been observed in other studies [44, 50]. However, there was no bacteriological or histological confirmation information (ICD A16.2) for the classification of death.
Regarding the methods of analysis used to identify the risk of mortality in the areas under study, both techniques showed spatial risk and protection clusters for the occurrence of death due to TB (Figs. 2, 3 and 4) in the same regions of the municipality, but with different conformations. The isotonic analysis produced spatial risk clusters with larger dimensions, grouping more census tracts and calculating a greater number of deaths, compared to the standard version. This finding corroborates a study carried out by Kulldorff [18] on breast cancer in the United States.

As highlighted in the results of the study, a spatial scan detects the general location of the cluster by treating the SRR as a constant value, whereas the isotonic version presents the steps in risk function, which stratifies the radius sizes and SRR values within the cluster. This allows for a better diagnosis of the mortality in the municipality and shows areas with real risks of the event or those that constitute regions of protection.

In addition to the discussion of protection clusters, which were identified by both analyses (traditional and 


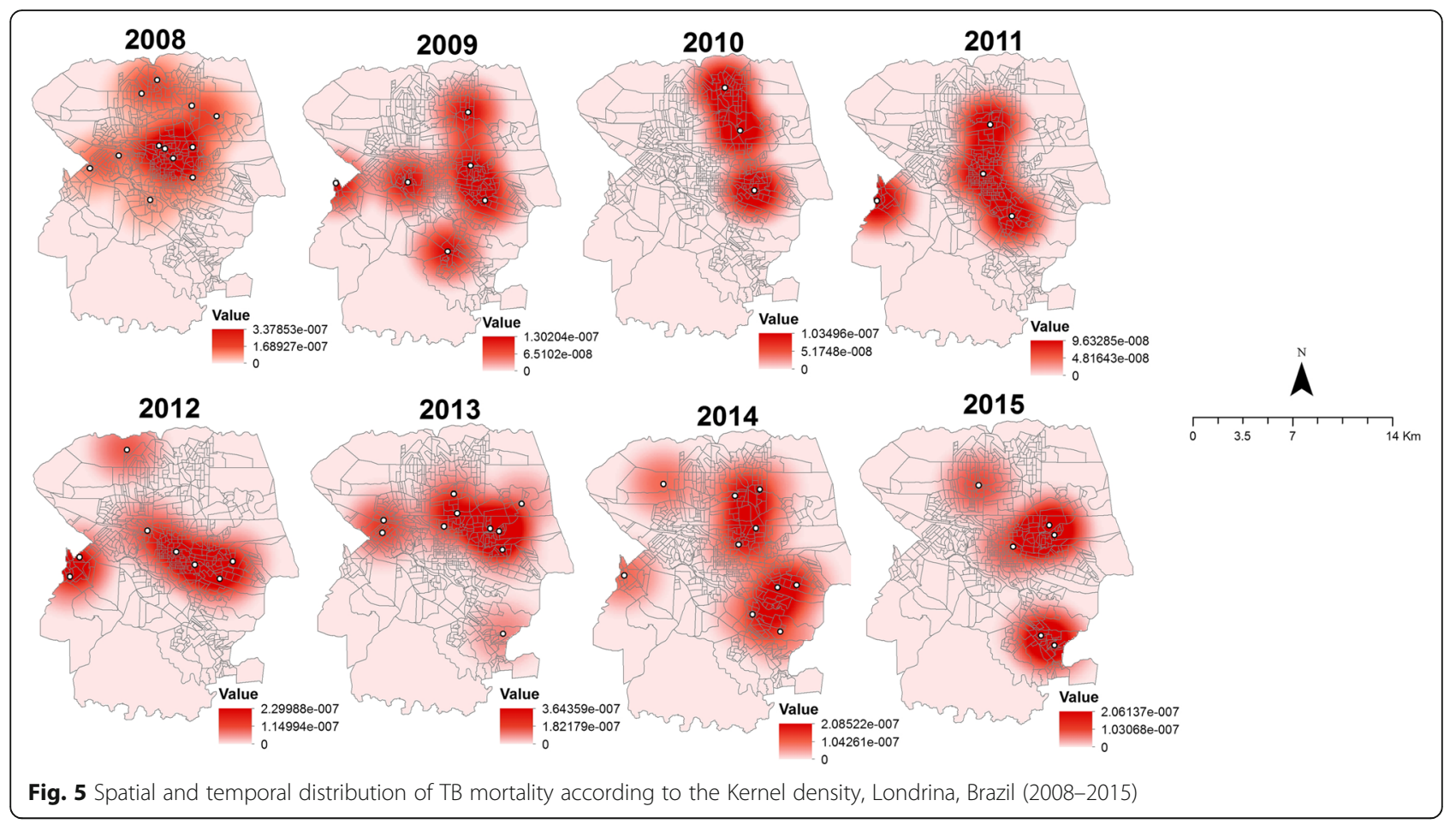

isotonic) and in the $\mathrm{Gi}^{*}$ analysis, large differences were not observed in terms of the protection areas when the approaches were compared. Specifically regarding the protection areas shown by the study, it should be mentioned that the results were derived from data generated by health services and, therefore, their existence may be due to the underreporting of $\mathrm{TB}$, although MIS is considered the gold standard throughout the country.

Through the kernel density analysis, there was little variation in the spatial distribution of deaths over time. Moreover, the areas of risk identified in the other spatial techniques remained the same, highlighting the eastern region, which continued to have a high density of deaths in all study years.

Mortality from tuberculosis can be influenced by the degree of integration between epidemiological surveillance activities and care provided over time, especially with regard to primary health care. Changes in health policies that do not focus on strengthening primary health care are commonly observed in Brazil. Therefore, mortality rates are also influenced by health actions, such as the training of health professionals to perform early diagnosis, the active search for respiratory symptomatology, and the follow-up of patients. In addition, local socioeconomic inequalities also suffer from variations in space-time, directly related with TB mortality.

This study worked with a small number of observations, since death due to $\mathrm{TB}$ is an infrequent phenomenon in the region. Thus, using traditional scan statistics might result in false negative areas of risk, which could compromise the surveillance actions of the city.

Since this study introduced alternative methods for diagnosing risk clusters and confirmed areas that were considered to be non-problematic, this study can become a reference for other small Brazilian municipalities (about 5,000 cities) where TB mortality may still be occult or silent. The application of the $\mathrm{Gi}^{*}$ and kernel methods is more frequent than the isotonic spatial scan statistic, yet, when they are used together, the results become much more consistent, reliable and valid.

A reduction in $\mathrm{TB}$ mortality requires an understating of the dynamics of TB at the local level, not only at the national or state levels. Since most Brazilian municipalities are small in size, new approaches, including geostatistics, are absolutely necessary to unravel some mysteries. Stevens and Pfeiffer [57] corroborate this idea by emphasising that innovative methodologies for a more congruous spatial approach to health enable the discovery of results that are more in line with the real situation and can provide guidance for health decision making.

The authors understand that the study might be a reference for diagnosing risk $\mathrm{TB}$ mortality and others rarer diseases, as well as a tool to guide policy makers, managers, stakeholders in the allocation of resources, such as cash transfers (Bolsa Família) and others social pockets according to the areas of highest risk $[1-3]$. 
The limitations of this study include the use of secondary data, which may have introduced bias due to the presence of gaps or incomplete data. It should also be noted that for the spatial analyses, only the cases of the deaths of individuals living in the urban area of the municipality were considered.

\section{Conclusions}

In conclusion, risk areas for tuberculosis mortality have been identified, including areas where TB was supposedly not a problem. These findings were achieved due to the combination of complementary methods. This study does not allow for a conclusion in terms of the best method for estimating the spatial risk for small regions, since the concepts and approach of each method are different. For this, a different study design would be necessary, with a focus on geostatistical analysis through simulations and more dense and robust tests. These findings show the need to match methods to confer more accurate results, specifically in areas where the phenomenon is rare.

\section{Abbreviations}

DD: Declaration of Death; FHS: Family Health Strategy; Gi*: Getis-Ord Gi* statistics; ICD: International Classification of Diseases; MHDI: Municipal Human Development Index; MIS: Mortality Information System; PHUs: Primary Health Units; TB: Tuberculosis; WHO: World Health Organization

\section{Acknowledgements}

We are grateful to the Municipal Secretariat for Health of Londrina, for the partnership and support that they provided in the materialisation of the study.

\section{Authors' contributions}

$L A^{*}$ was responsible for performing the data collection, analysing and interpreting the data, and drafting and editing the article. DS, MA, TB and LA were responsible for data analysis, and helped to revise the article. $A R, I A$, $A Q$, and JA1 analysed the data. JA2, MP, MY, JC and ED designed the study and revised the article. PP, FC, CN and RA critically revised and polished the article, and also contributed to designing the research. RA conceived and directed the research, revising the article. All authors have read and approved the final manuscript and approve of the publication.

\section{Funding}

Alves, LS received financial assistance for partial expenses of the from the São Paulo Research Foundation (Process number: 2015/17586-3) and Coordination for the Improvement of Higher Education Personnel.

\section{Availability of data and materials}

Mortality data that were the basis for this study belong to the Department of Epidemiology of the Health Secretariat of Londrina.

\section{Ethics approval and consent to participate}

The study was approved by the Human Research Ethics Committee of the University of São Paulo at Ribeirão Preto College of Nursing, CAAE 56305516.0.0000.5393, issued on 11 December 2015. The Committee accepted a statement with justification for the waiver of the consent term due to the fact that the research was carried out with secondary data from the MIS and the IBGE. The Brazilian legislation regarding Resolution 466/2012 was respected.

\section{Consent for publication}

Not applicable.

\section{Competing interests}

The authors declare that they have no competing interests.

\section{Author details}

${ }^{1}$ Nursing Graduate Program in Public Health Nursing, University of São Paulo at Ribeirão Preto Nursing College, 3900 Avenida dos Bandeirantes, São Paulo, Brazil. ${ }^{2}$ Inter-institutions Doctoral Program in Nursing, University of São Paulo at Ribeirão Preto Nursing College, São Paulo, Brazil. ${ }^{3}$ Public Health, Natal, Rio Grande do Norte, Brazil. 'University of São Paulo at Ribeirão Preto Nursing College, São Paulo, Brazil. ${ }^{5}$ Department of Nursing, Fasipe School, Mato Grosso, Brazil. ${ }^{6}$ Department of Nursing, Londrina State University, Londrina, Paraná, Brazil. " Department of Epidemiology, School of Public Health, University of São Paulo, São Paulo, São Paulo, Brazil. ${ }^{8}$ National School of Public Health, Nova University of Lisbon, Lisboa, Portugal. ${ }^{9}$ Maternal-Infant and Public Health Nursing Department, University of São Paulo at Ribeirão Preto College of Nursing, Av dos Bandeirantes 3900, Ribeirão Preto, São Paulo 14040-902, Brazil.

Received: 22 March 2019 Accepted: 4 July 2019

Published online: 17 July 2019

\section{References}

1. World Health Organization. Global Tuberculosis Report 2018. Geneva: WHO press, World Health Organization; 2017. http://apps.who.int/iris/bitstream/1 0665/259366/1/9789241565516-eng.pdf?ua=1. Accessed 12 Dec 2017

2. Brasil. Ministério da Saúde Secretaria de Vigilância em Saúde Departamento de Vigilância das Doenças Transmissíveis Coordenação Geral do Programa Nacional de Controle da Tuberculose 2017. http://portalarquivos.saude.gov. br/images/pdf/2017/fevereiro/24/Plano-Nacional-Tuberculose.pdf. Accessed 12 Dec 2017.

3. World Health Organization. Global Tuberculosis Report 2017. Geneva: WHO press, World Health Organization; 2017. http://apps.who.int/medicinedocs/ documents/s23098en/s23098en.pdf. Accessed 12 Dec 2017

4. Albuquerque M d FPM d, Batista J d'A L, Ximenes RA d A, Carvalho MS, GTN D, Rodrigues LC. Risk factors associated with death in patients who initiate treatment for tuberculosis after two different follow-up periods. Rev Bras Epidemiol. 2009;12:513-22.

5. Berra TZ, Queiroz AA, Yamamura M, Arroyo LH, Garcia MC, Popolin MP, Santos DT, Ramos AC, Alves LS, Fronteira IE, Chiaravalloti NF. Spatial risk of tuberculosis mortality and social vulnerability in Northeast Brazil. Rev Soc Bras Med Trop. 2017;50(5):693-7.

6. Santos-Neto M, Yamamura M, Garcia MCC, Popolin MP, Rodrigues LBB, Chiaravalloti Neto F, et al. Pulmonary tuberculosis in São Luis, state of Maranhão, Brazil: space and space-time risk clusters for death (2008-2012). Rev Soc Bras Med Trop. 2015;48(I1):69-76.

7. Yamamura M, Santos-Neto M, Santos RA, Garcia MC, Nogueira JD, Arcêncio RA. Epidemiological characteristics of cases of death from tuberculosis and vulnerable territories. Rev Latinoam Enferm. 2015;23(5):910-8.

8. Elliot P, Wakefield JC, Best NG, Briggs DJ. Spatial epidemiology: methods and applications. Oxford: Oxford University Press; 2000.

9. Grubesic TH, Wei R, Murray AT. Spatial clustering overview and comparison: accuracy, sensitivity, and computational expense. Ann Assoc Am Geogr. 2014;104(6):1134-56

10. Rothman K, Greenland S, Lash TL. Modern Epidemiology. 3rd ed. Philadelphia: Lippincott Williams \& Wilkins; 2008.

11. Prefeitura do município de Londrina. Secretaria Municipal de Saúde. Plano Municipal de Saúde 2014-2017. 2015. http://www1.Iondrina.pr.gov.br/dados/ images/stories/Storage/sec_saude/Plano\%20Municial/plano_municipal_de_ saude_2014_2017.pdf. Accessed 12 Dec 2017.

12. Instituto Paranaense de Desenvolvimento Econômico e Social (IPARDES). Caderno Estatístico municipio de Londrina. 2016. http://www.ipardes. gov.br/cadernos/MontaCadPdf1.php? Municipio $=86000 \& b t O k=0 k$. Accessed 12 Dec 2017.

13. Programa das Nações Unidas para o Desenvolvimento. Atlas do Desenvolvimento Humano nas Regiões Metropolitanas Brasileiras. - Brasília: PNUD, Ipea, FJP, 2014. http://www.atlasbrasil.org.br/2013/data/rawData/ publicacao_atlas_rm.pdf. Accessed 12 Dec 2017.

14. Brasil. Ministério da Saúde. Secretaria de vigilância em saúde. Panorama da tuberculose no Brasil. 2014. Accessed 12 Dec 2017.

15. Instituto Brasileiro de Geografia e Estatística. Censo demográfico 2010: resultados gerais da amostra. IBGE. 2012. http://www.ibge.gov.br/home/ 
estatistica/populacao/censo2010/resultados_gerais_amostra/default_ resultados_gerais_amostra.shtm. Accessed 12 Dec 2017.

16. Rocha MS, de Oliveira GP, Aguiar FP, Saraceni V, Pinheiro RS, Rocha MS, et al. Do que morrem os pacientes com tuberculose: causas múltiplas de morte de uma coorte de casos notificados e uma proposta de investigação de causas presumíveis. Cad Saúde Pública. 2015;31(4):709-21.

17. Kulldorff M, Nagarwalla N. Spatial disease clusters: detection and inference. Stat Med. 1995;14:799-810.

18. Kulldorff M. An isotonic spatial scan statistic for geographical disease surveillance. J Natl Inst Public Heal. 1999:48:94-101.

19. Olfatifar M, Karami M, Hosseini SM, Parvin M. Clustering of pulmonary tuberculosis in Hamadan province, western Iran: A population based cross sectional study (2005-2013). J Res Health Sci. 2016;16(3):166-9.

20. DE Lucena EFS, Moraes RM. Detecção de agrupamentos espaço-temporais para identificação de áreas de risco de homicídios por arma branca em João Pessoa, PB. Boletim de Ciências Geodésicas. 2012;18:605-23.

21. Waller LA, Gotway CA. Applied spatial statistics for public health data. Georgia: Wiley; 2004.

22. Gao F, Abe EM, Li S, Zhang L, He J-C, Zhang S, et al. Fine scale spatialtemporal cluster analysis for the infection risk of schistosomiasis japonica using space-time scan statistics. Parasit Vectors. 2014;7:578.

23. Jardine CG. Role of risk communication in a comprehensive risk management approach. Encycl Quant Risk Anal Assess. 2008:1584-7.

24. Prates MO, Kulldorff M, Assunção RM. Relative risk estimates from spatial and space-time scan statistics: are they biased? Stat Med. 2014;33(Suppl 15):2634-44

25. Li XZ, Wang JF, Yang WZ, Li ZJ, Lai SJ. A spatial scan statistic for nonisotropic two-level risk cluster. Stat Med. 2012;31:177-87.

26. Kulldorff M, Alessandra T, Guedes C. SaTScan TM Manual do Usuário. 2016 https://www.satscan.org/cgi-bin/satscan/register.pl/SaTScan_Users_Guide. pdf?todo=process_userguide_download. Accessed 12 Dec 2017.

27. Wagner MB, Callegari-Jacques SM. Medidas de associação em estudos epidemiológicos: risco relativo e odds ratio. J Pediatr. 1998;74(Suppl 3):247-51.

28. Azage M, Kumie A, Worku A, Bagtzoglou AC. Childhood Diarrhea Exhibits Spatiotemporal Variation in Northwest Ethiopia: A SaTScan Spatial Statistical Analysis. Odoi A, editor. PLoS One. 2015;10:e0144690

29. Sluydts V, Heng S, Coosemans M, Van Roey K, Gryseels C, Canier L, et al. Spatial clustering and risk factors of malaria infections in Ratanakiri Province, Cambodia Malar. J BioMed Central. 2014;13:387-99.

30. Stopka TJ, Goulart MA, Meyers DJ, Hutcheson M, Barton K, Onofrey S, et al. Identifying and characterizing hepatitis C virus hotspots in Massachusetts: a spatial epidemiological approach. BMC Infect. Dis. 2017;17(Suppl 1):294.

31. Zhang Y, Shen Z, Ma C, Jiang C, Feng C, Shankar N, et al. Cluster of human infections with avian influenza A (H7N9) cases: a temporal and spatial analysis. Int J Environ Res Public Health. 2015;12:816-28.

32. Getis A, Ord JK. The analysis of spatial association. Geogr Anal. 1992;24:189-206.

33. Wang T, Xue F, Chen Y, Ma Y, Liu Y. The spatial epidemiology of tuberculosis in Linyi City, China, 2005-2010. BMC Public Health. 2012;12:885.

34. Abedi-Astaneh F, Hajjaran H, Yaghoobi-Ershadi MR, Hanafi-Bojd AA, Mohebali M, Shirzadi MR, et al. Risk Mapping and Situational Analysis of Cutaneous Leishmaniasis in an Endemic Area of Central Iran: A GIS-Based Survey. Munderloh UG, editor. PLoS One. 2016;11:e0161317 Public Library of Science.

35. Câmara G, Monteiro AM, Fucks SD, Carvalho MS. Análise espacial e geoprocessamento. Análise espacial de dados geográficos; 2002.

36. Davies TM, Hazelton ML. Adaptive kernel estimation of spatial relative risk. Stat Med. 2010:29(23):2423-37.

37. Arcêncio RA, Arakawa T, Oliveira MF, Cardozo-Gonzales RI, Scatena LM, Ruffino-Netto A, Villa TC. Barreiras econômicas na acessibilidade ao tratamento da tuberculose em Ribeirão Preto-São Paulo. Rev Esc Enferm USP. 2011:45(5):1121-7.

38. Arcêncio RA, Oliveira MF, Cardozo-Gonzales RI, Ruffino-Netto A, Pinto IC, Villa TC. City tuberculosis control coordinators' perspectives of patient adherence to DOT in São Paulo state, Brazil, 2005. Int J Tuberc Lung Dis. 2008;12(5):527-31 38.

39. Augusto CJ, Carvalho Wda S, Goncalves AD, Ceccato M d, Miranda SS, et al. Characteristics of tuberculosis in the state of Minas Gerais, Brazil: 2002-2009. J Bras Pneumol. 2013;39:357-64 Sociedade Brasileira de Pneumologia e Tisiologia

40. Cecilio HPM, Molena-Fernandes CA, Mathias TA d F, Marcon SS. Perfil das internações e óbitos hospitalares por tuberculose. Acta Paul Enferm. 2013;26:250-5.
41. Yen Y-F, Feng J-Y, Pan S-W, Chuang P-H, Su VY-F, Su W-J. Determinants of mortality in elderly patients with tuberculosis: a population-based follow-up study. Epidemiol Infect. 2017;145:1374-81.

42. Qi Z, Yang W, Wang Y-F. Epidemiological analysis of pulmonary tuberculosis in Heilongjiang province China from 2008 to 2015. Int J Mycobacteriol. 2017;6:264.

43. Raimundo AG, Guimarães AM, Nery A, Silva SC. Tuberculose: o perfil no novo milênio. Rev Enferm UFPE line. 2015;10:1387-96.

44. Dale K, Tay E, Trevan P, Denholm JT. Mortality among tuberculosis cases in Victoria, 2002-2013: case fatality and factors associated with death. Int J Tuberc Lung Dis. 2016;20:515-23.

45. Beyene Y, Geresu B, Mulu A. Mortality among tuberculosis patients under DOTS programme: a historical cohort study. BMC Public Health. 2016;16:883.

46. Ferrer GCN, da Silva RM, Ferrer KT, Traebert J, Ferrer GCN, da Silva RM, et al. The burden of disease due to tuberculosis in the state of Santa Catarina. Brazil J Bras Pneumol. 2014;40:61-8.

47. Ceccon RF, Maffacciolli R, Burille A, Meneghel SN, de Oliveira DLLC, Gerhardt TE, et al. Mortalidade por tuberculose nas capitais brasileiras, 2008-2010. Epidemiol Serv Saúde. 2017;26(2):349-58.

48. Cardoso JN. Perfil epidemiológico e fatores associados ao óbito por tuberculose em Teresina; 2015.

49. Dessunti EM, Meier DA, Donath BC, Costa AA, Guariente MH. Infecção latente de tuberculose: adesão ao tratamento e evolução dos casos. Rev Enferm UERJ. 2013;21:711-7.

50. Sánchez-Barriga JJ. Tendencias de mortalidad y riesgo de muerte por tuberculosis pulmonar en las 7 regiones socioeconómicas y los 32 estados de México, 2000-2009. Arch Bronconeumol. 2015;51:16-23.

51. Blöndal K, Rahu K, Altraja A, Viiklepp P, Rahu M, Blöndal K. Overall and cause-specific mortality among patients with tuberculosis and multidrugresistant tuberculosis. Int J Tuberc Lung Dis. 2013;17:961-8.

52. Lin Y-S, Yen Y-F. Determinants of mortality before start of and during tuberculosis treatment among elderly patients: a population-based retrospective cohort study. Age Ageing. 2015;44(3):490-6.

53. Oliveira Cavalcante EF, Guerreiro Vieira da Silva DM. Profile of Tuberculosis Patients Perfil De Personas Acometidas Por Tuberculosis. Revista da Rede de Enfermagem do Nordeste. 2013;14(4):1-10.

54. Salinas J, Calvillo S, Caylà J, Nedel FB, Martín M, Navarro A, et al. Delays in the diagnosis of pulmonary tuberculosis in Coahuila, Mexico. Int J Tuberc Lung Dis. 2012;16:1193-8.

55. Saifodine A, Gudo PS, Sidat M, Black J. Patient and health system delay among patients with pulmonary tuberculosis in Beira city, Mozambique. BMC Public Health. 2013;13:559.

56. Theron G, Jenkins HE, Cobelens F, Abubakar I, Khan AJ, Cohen T, et al. Data for action: collection and use of local data to end tuberculosis. Lancet. 2015;386:2324-33

57. Stevens KB, Pfeiffer DU. Spatial modelling of disease using data- and knowledge-driven approaches. Spat Spatiotemporal Epidemiol. 2011;2:125-33.

\section{Publisher's Note}

Springer Nature remains neutral with regard to jurisdictional claims in published maps and institutional affiliations.

Ready to submit your research? Choose BMC and benefit from:

- fast, convenient online submission

- thorough peer review by experienced researchers in your field

- rapid publication on acceptance

- support for research data, including large and complex data types

- gold Open Access which fosters wider collaboration and increased citations

- maximum visibility for your research: over $100 \mathrm{M}$ website views per year

At BMC, research is always in progress.

Learn more biomedcentral.com/submissions 